\title{
Applying Multinational Association of Supportive Care of Cancer Index Score for Identifying Febrile Neutropenia Patients at High Risk of Complications at Tertiary Care Hospital, Pakistan
}

\author{
Zarka Samoon1*, Madiha Beg2*, Munira Shabbir Moosajee1, Mahwish Kamran1, Nehal Masood1, \\ Afshan Asghar', Adeel Ahmed ${ }^{1}$
}

${ }^{1}$ Department of Oncology, The Aga Khan University Hospital, Karachi, Pakistan

${ }^{2}$ Department of Radiology, The Aga Khan University Hospital, Karachi, Pakistan

Email: `zarka.samoon@aku.edu, ^madiha.beg@aku.edu, munira.moosajee@aku.edu,drmaha_wish@hotmail.com,

nehal.masood@aku.edu, afshan.asghar@aku.edu, adeel.ahmed@aku.edu

How to cite this paper: Samoon, Z., Beg, M., Moosajee, M.S., Kamran, M., Masood, N., Asghar, A. and Ahmed, A. (2017) Applying Multinational Association of Supportive Care of Cancer Index Score for Identifying Febrile Neutropenia Patients at High Risk of Complications at Tertiary Care Hospital, Pakistan. Open Journal of Epidemiology, 7, 159-174.

https://doi.org/10.4236/ojepi.2017.72014

Received: March 14, 2017

Accepted: May 15, 2017

Published: May 19, 2017

Copyright (c) 2017 by authors and Scientific Research Publishing Inc. This work is licensed under the Creative Commons Attribution International License (CC BY 4.0).

http://creativecommons.org/licenses/by/4.0/

\section{(c) (i) Open Access}

\begin{abstract}
Introduction: Multinational Association of Supportive Care of Cancer (MASCC) index score is a clinical tool to predict outcomes in Febrile Neutropenia patients. This risk-index score has been authenticated in international trials however local data is deficient. We aimed to determine hospital based incidence rate of serious complications in admitted chemotherapy induced febrile neutropenia patients presenting to a tertiary care hospital. We also aimed to compare proportions of serious medical complications in patients having MASCC score $<21$ or $\geq 21$. Methods: A hospital based prospective close cohort study was designed and conducted at Oncology wards of The Aga Khan University from February to August 2014. Total of 88 patients, aged 16 and above, with chemotherapy induced febrile neutropenia were identified and divided on the basis of MASCC Score into low or high risk \{exposure\} groups. Follow up was done from day of admission (day zero) to discharge. Outcome was assessed in terms of development of serious complications. Hospital based incidence rate was estimated. The associations between outcome and qualitative variables were evaluated by using Pearson Chi-square and Fisher's exact test. Results: Hospital based incidence rate of febrile neutropenia admission was $5.98 \%$, 95\%CI [ $4.88 \%-7.08 \%$ ]. Out of 88 patients with chemotherapy induced febrile neutropenia $85.2 \%$ patients were in the high risk group and $14.8 \%$ in the low risk group. Serious complications were found in $21.33 \%$ and no patients in high and low risk group respectively. Age $>60(\mathrm{p}=0.039)$,
\end{abstract}


MASCC score $<15(\mathrm{p}=0.002)$ and an albumin $<2.5 \mathrm{mg} / \mathrm{dl}(\mathrm{p}=0.046)$ was associated with higher chance of developing serious complications. Sensitivity, specificity, positive and negative predictive value of MASCC score in predicting risk of serious complications was $21.33 \%, 100 \%, 100 \%$ and $18.06 \%$ respectively. Conclusion: MASCC risk-index score is a useful tool to identify patients at low risk of complications. Hospital based incidence rate of serious complications was $18.2 \%$.

\section{Keywords}

Febrile Neutropenia, Chemotherapy, Serious Complications

\section{Introduction}

Febrile neutropenia (FN) is a common complication of chemotherapy. It is considered a medical emergency, in general requiring hospital admission and broad spectrum empiric antibiotics [1]. Among patients receiving chemotherapy $10 \%$ $50 \%$ of patients with solid tumours and $80 \%$ of those with hematologic malignancies are said to develop FN [2]. Around 10\% - 25\% patients have documented bacteraemia with most patients having prolonged or severe neutropenia [3] [4] [5]. Such episodes lead to delay in treatment which may compromise outcomes in potentially treatable tumours [6]. Febrile neutropenia may be potentially lethal, with one study reporting inpatient mortality with FN as high as 9.5\% [7]. Mortality varies from 5\% in patients with solid tumours to around $11 \%$ in patients with haematological tumours [8]. Factors associated with high risk of mortality include pneumonia, invasive fungal infections, lung disease, renal disease, liver disease, cerebrovascular disease, congestive cardiac failure, pulmonary embolism and lung carcinoma [7]. Factors associated with a favourable outcome are said to be an albumin level of $>2.5 \mathrm{mg} / \mathrm{dl}$, low disease burden, and an absence of respiratory infection [9]. Proven bacteraemia is associated with worst outcomes, with mortality rates of $5 \%$ in Gram-positive bacteraemia and $18 \%$ in Gram-negative bacteraemia [8].

Various instruments have been established to predict which cases are at high risk for complications. The purpose of such models is to predict the risk of complications at the commencement of FN episode, and to recognize which patient subset would be eligible for outpatient management and less intensive antibiotic therapy. Two such models have been used for risk stratification, which include the Talcott's model and Multinational Association for Supportive Care in Cancer (MASCC) scoring system [10] [11]. Multinational Association of Supportive Care of Cancer (MASCC) index score was developed by Klastersky et al. in 2000 to stratify patients into high or low risk and predict their possible outcome, with a score of 21 or more putting the patient at low risk of complications and mortality [11]. The results of this study predicted low risk patients (with a risk index score of $\geq 21$ ) with a positive predictive value of $91 \%$, specificity of $68 \%$, and sensitivity of $71 \%[11]$. 
Baskaran et al. reported a total of 116 cases of febrile neutropenia out of whom medical complications occurred in $34 \%$ of cases. Of the patients identified as low risk, $17.1 \%$ developed serious medical complications while patients in the high-risk group, $85 \%$ developed serious medical complications [9].

There have been various prospective studies to validate the MASCC scoring system; however most of them have been conducted in developed countries [9] [11]. Hence we carried out this study to assess if MASCC scores of high risk and low risk and consequently high or low risk of complications are applicable in our part of the world. By identifying patients at low risk of complications, a less aggressive treatment may be given (early hospital discharge or outpatient therapy), thus reducing the cost of hospital stay, chances of overtreatment and appropriate use of resources and at the same time, identifying patients with high risk and appropriately treating them [12].

The MASCC risk index score is based on seven independent factors, present at the beginning of FN episode. These seven factors and their weight are given in Table 1.

The list of serious complications is detailed in Table 2. We hypothesized that patients with low MASCC score are at a higher risk of developing serious complications as compared to those with a high score. The primary objective of this study was to estimate hospital based incidence rate of serious complications in cancer patients admitted with febrile neutropenia.

We also aimed to compare proportions of serious medical complications in patients having MASCC score $<21$ or $\geq 21$.

\section{Methods}

\subsection{Overview and Study Participants}

We adopted a prospective close cohort study design to collect data from Febru-

Table 1. Multinational Association for Supportive Care in Cancer (MASCC) risk model $(9)^{*}$.

\begin{tabular}{lc}
\hline \multicolumn{1}{c}{ Prognostic Factor } & Weight \\
\hline $\begin{array}{l}\text { Burden of febrile neutropenia illness: no or mild symptoms (less than two organ } \\
\text { symptoms, not requiring intervention) }\end{array}$ & 5 \\
No hypotension & 5 \\
No chronic obstructive pulmonary disease & 4 \\
Solid tumor or no previous fungal infection (in patients with haematological malignancies.) & 3 \\
No dehydration & 3 \\
Burden of febrile neutropenia illness: moderate symptoms (more than two organ systems \\
or less than two organ systems but requiring intervention) \\
$\begin{array}{l}\text { Outpatient status } \\
\text { Age }<60 \text { years }\end{array}$ \\
$\begin{array}{l}* \text { The overall score is calculated by adding the individual points, with maximum score of } 26 \text { points. A score } \\
\text { of } \geq 21 \text { is defined as low risk and }<21 \text { as high risk. }\end{array}$
\end{tabular}


Table 2. Rate of Serious complications.

\begin{tabular}{ccc}
\hline & High risk $(\mathbf{n}=\mathbf{7 5})$ & Low risk $(\mathbf{n}=\mathbf{1 3})$ \\
\hline Serious complications [n(\%)] & $16(21 \%)$ & 0 \\
Hypotension & 9 & - \\
Respiratory failure & 8 & - \\
ICU admission & 3 & - \\
DIC & 1 & - \\
Confusion & 3 & - \\
CCF & 2 & - \\
Bleeding & 2 & - \\
Renal failure & 4 & $4(1-7)$ \\
Death & 9 &
\end{tabular}

ary to August 2014 from the Oncology wards of The Aga Khan University (where both haematology and solid tumours are treated) which is one of the tertiary care hospitals in Karachi, Pakistan receiving patients from all over the country. We recruited a cohort of 88 chemotherapy induced febrile neutropenia patients aged 16-years and above of either gender using consecutive sampling methodology. They were enrolled at their index visit via emergency or oncology clinic requiring ward admission. These patients were followed from the day of hospital admission till discharge.

Patients with confirmed diagnosis of cancer and having history of receiving chemotherapy prior to episode of febrile neutropenia were included. They were excluded if the adult patient presented with febrile neutropenia as a result of their underlying disease, like, aplastic anaemia and myelodysplastic syndrome. Also, patients with no history of chemotherapy were excluded.

\subsection{Ethics Statement}

Our study protocol was initially accepted from the Ethical Review Committee of our institution with ERC \# 2948-Med-14. Therefore, written informed consent was taken from patients before asking them for study participation.

\subsection{Ascertainment of Exposure}

Trained interviewers screened and enrolled participants within 48 hours of hospital admission based on the standard definition of febrile neutropenia episode with a single oral temperature of $38.3^{\circ} \mathrm{C}$ or, oral temperature of $38^{\circ} \mathrm{C}$ which persists for more than an hour and an absolute neutrophil count of $<1000$ cells $/ \mathrm{mm}^{3}$ [1]. Patients were stratified into high \{exposed and low risk \{non-exposed based on MASCC score at the time of admission. The MASCC Score is calculated based on burden of illness, presence of hypotension, chronic obstructive pulmonary disease, fungal infection, solid tumor, outpatient status and age $<60$ years [Table 1]. 


\subsection{Ascertainment of Outcome}

Patient outcome was recorded by the trained interviewers as development of serious complications or not at the time of hospital discharge, based on presence or absence of any of the following: hypotension, respiratory failure, intensive care admission, disseminated intravascular coagulation, confusion or altered mental state, congestive cardiac failure, bleeding and renal failure. Length of hospital stay was recorded on discharge. Positive cultures were also recorded.

\subsection{Covariables}

Following covariables were recorded for each patient including demographic information, underlying cancer and chemotherapy, day one of chemotherapy, absolute neutrophil count (ANC), foci of infection, including any positive cultures. The application of G-CSF non-usage versus usage [along with the total number of days administered] was noted.

\subsection{Operational Definitions Taken into Account}

Patients were stratified as high risk if they had a MASCC score of less than 21 and low risk if score is equal to or more than 21 based on parameters mentioned in Table 1 [11]. Serious complications [10] were defined as a presence of any one of the following: Hypotension if systolic blood pressure $<90 \mathrm{~mm} \mathrm{Hg}$, respiratory failure if arterial oxygen pressure $<60 \mathrm{~mm} \mathrm{Hg}$ while breathing room air or a need for mechanical ventilation. Intensive care unit admission for hypotension with systolic blood pressure $<90 \mathrm{~mm} \mathrm{Hg}$ or respiratory failure with an arterial oxygen pressure $<60 \mathrm{~mm} \mathrm{Hg}$ while breathing room air or a need for mechanical ventilation. Disseminated intravascular coagulation (prothrombin time $>14$ seconds and activated prothrombin thromboplastin time $($ PTT) $>35$ seconds, fibrinogen levels $<150 \mathrm{mg} / \mathrm{dl}$, fibrin degradation products $>20$ microgram $/ \mathrm{ml}$ and d-dimer $>0.8 \mathrm{mg} / \mathrm{l})$.

Confusion was defined as (assessed by Confusion Assessment Method diagnostic algorithm based on the presence of two factors: (i) acute onset and fluctuating course and (ii) inattention and presence of any one of the following two factors: (a) disorganized thinking (b) altered level of consciousness [13]. Congestive cardiac failure, as seen on chest X-ray as bilateral lung infiltrates; requiring treatment with diuretics. Bleeding, severe enough to require one packed red cell transfusion. Renal failure defined as increase in Serum Creatinine of 0.3 $\mathrm{mg} / \mathrm{dl}$ within 48 hours [14]. Data collection schema has been illustrated in Figure 1.

\subsection{Sample Size Assumptions}

The sample size was calculated by taking into consideration the study objectives. Epi Info Version 6 was utilized to compute the sample size. The calculations were based on the assumption that reported proportion of serious complication for febrile neutropenia is $34 \%$ [9]. By taking into account this figure together 


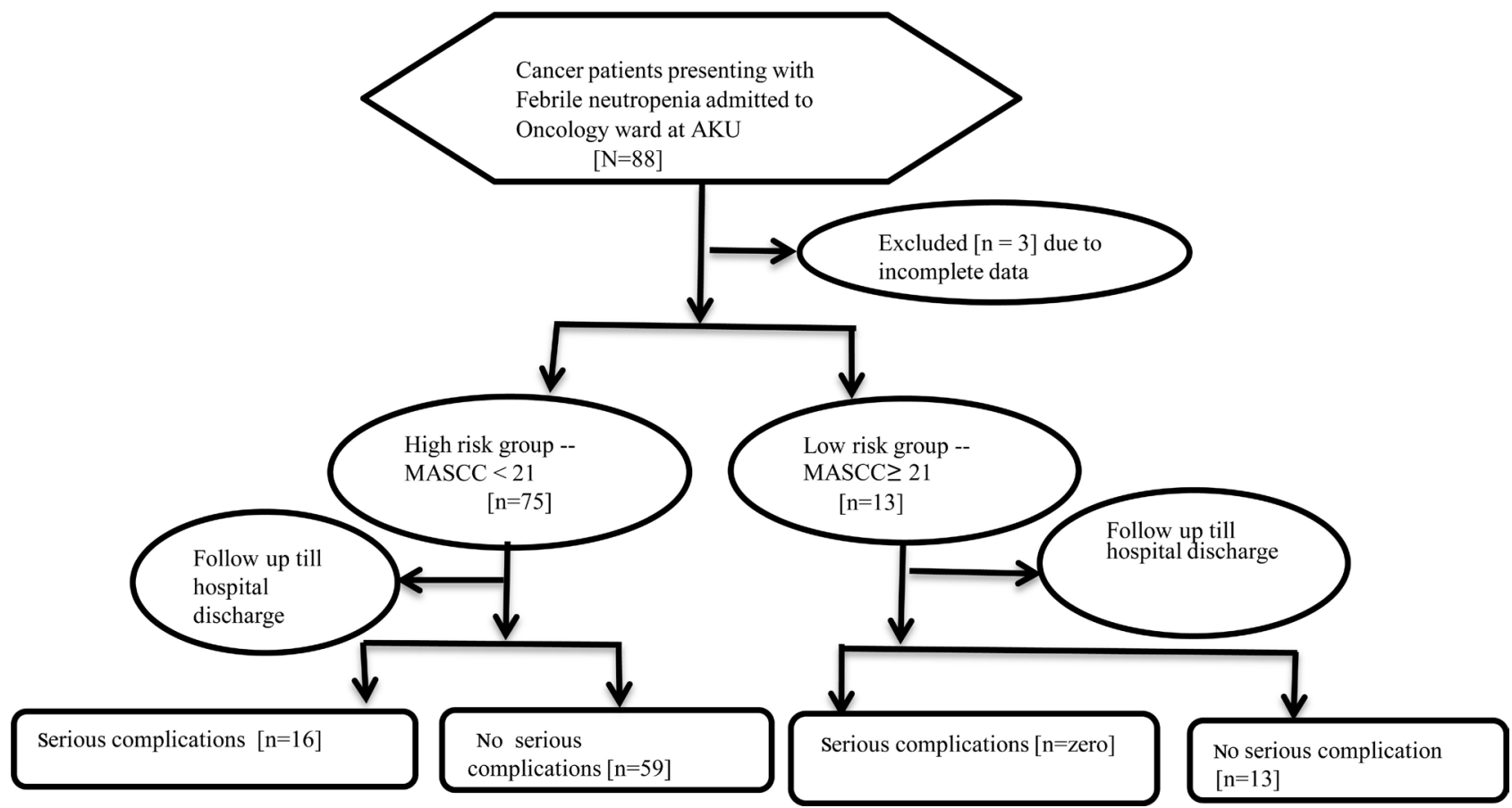

Figure 1. Schematic depiction of study flow chart.

with $95 \% \mathrm{CI}$, and exposed to non-exposed ratio of $1: 1$, with $80 \%$ power and risk ratio of 2.0, the sample size calculated to be $n=76$. After adjusting for missing or incomplete information, the final sample size was approximately $\mathrm{N}=84$.

\subsection{Data Analysis Plan}

Data were entered and analysed in Statistical Package for Social Sciences 20.0 version. (SPSS, Inc., Chicago, IL, USA). Descriptive analysis were run to compute frequencies and proportions for categorical variables like gender, presence or absence of each serious complications (hypotension, respiratory failure, intensive care unit admission, bleeding, disseminated intravascular coagulation, congestive cardiac failure, confusion or altered mental status and death). Means and standard deviations were calculated for quantitative variables.

Number and proportions were calculated for complications in patients with MASCC score $\geq 21$ and $<21$. Hospital based incidence rate of serious complications was computed. $\chi^{2}$ or Fischer's Exact test were applied to categorical variables like age, gender, tumour, albumin, ANC, MASCC Score, Microbiology and G-CSF use. Independent samples $t$ test was applied to assess difference between mean length of hospital stay and serious complications A p-value of $<0.005$ was taken significant for inferential statistics. A $2 \times 2$ table was employed for calculation of sensitivity, specificity, positive and negative predictive values of MASCC score in accurately predicting risk of serious complications. $95 \%$ confidence intervals were computed for the estimates.

\section{Results}

Data were collected for patients admitted with chemotherapy induced febrile 
neutropenia. A thorough review of the hospital medical records system revealed a total of 1471 patients who received chemotherapy between February till August 2014. However among these patients only 88 patients were admitted with chemotherapy induced febrile neutropenia and included for analysis (Figure 1). Thus we compute hospital based incidence rate of occurrence of chemotherapy induced febrile neutropenia to be $5.98 \%,\{88 / 1471\}, 95 \%$ CI $[4.88 \%-7.08 \%]$. Hospital based incidence rate of serious complications in these admitted febrile neutropenia patients was $18.2 \%, 95 \%$ CI [11.5\% - 25\%]. The mean age of inducted patients was $45.51 \pm 15.69$ years; range 17 - 75 years. The sample comprised of slightly higher preponderance of males 49 (55.7\%). The mean day of febrile neutropenia was $10.26 \pm 5.42$ days. A total of 75 (85.2\%) patients were categorized into high risk (exposed group) and 13 (14.8\%) into low risk (non-exposed group) based on criteria defined earlier. Among the high risk patients 16 (21.33\%) developed serious complications while none of the patients among low risk developed serious complications. Baseline characteristics based on risk status are given in Table 3. The rate of serious complications is enlisted in Table 2. Hypotension, respiratory failure and death were the most common complications.

\subsection{Tumour Types}

Forty nine (55\%) presented with haematological malignancies and 39 (44.3\%) with solid tumours. The most common chemotherapy prescribed for solid tumors was Doxorubicin and Cyclophosphamide, received by five patients. The most common chemotherapy in patients with haematological tumors was Rituximab, Cyclophosphamide, Vincristine, Doxorubicin and Prednisolone, received by six patients.

Table 3. Baseline characteristics based on low and high risk MASCC group.

\begin{tabular}{|c|c|c|}
\hline Characteristics & High risk & Low risk \\
\hline Number of patients $n(\%)$ & $75(85.2 \%)$ & $13(14.8 \%)$ \\
\hline Median age in years (range) & $48(17-75)$ & $53(18-63)$ \\
\hline \multicolumn{3}{|l|}{ Gender } \\
\hline Male & $42(56 \%)$ & $7(54 \%)$ \\
\hline Female & $33(44 \%)$ & $6(46 \%)$ \\
\hline \multicolumn{3}{|l|}{ Tumor } \\
\hline Solid & $34(45.3 \%)$ & $5(38.5 \%)$ \\
\hline Haematological tumors & $41(54.7 \%)$ & $8(61.5 \%)$ \\
\hline Mean Haemoglobin gm/dl (range) & $9.73(6.1-18.1)$ & $9.62(8-11.4)$ \\
\hline \multicolumn{3}{|l|}{ Absolute Neutrophil Count (cells $/ \mu \mathrm{L}$ ) } \\
\hline$<100$ & $62(82.7 \%)$ & $10(76.9 \%)$ \\
\hline$>100$ & $13(17.3 \%)$ & $3(23.1 \%)$ \\
\hline Mean Platelet (range) (cells $/ \mu \mathrm{L})$ & $99(1-500)$ & $67(3-227)$ \\
\hline
\end{tabular}




\subsection{Outcome Based on Covariates (Tumour Type, Positive Bacteraemia, Length of Hospital Stay, ANC and Age)}

Among the 49 patients who presented with haematological tumours, 8 (16.3\%) developed serious complications and among the 39 patients with solid tumours 8 (25.8\%) developed serious complications ( $\chi^{2}$ test statistic: $0.256, \mathrm{df}=1, \mathrm{p}=$ $0.613)$.

Among the entire sample of 88 patients, 23 patients had positive cultures. Amid the high risk group a total of 17 (22.6\%) patients' revealed bacteraemia. Out of these 17 patients, 2 (11.7\%) patients died. In contrast, 6 (46.1\%) patients in the low risk group had bacteraemia and none of them died. However no statistically significant difference was established among the low and high risk group in terms of positive cultures and outcome (serious complication). ( $\chi^{2}$ test statistic: $0.23, \mathrm{df}=3, \mathrm{p}=0.97$ ).

The mean length of hospital stay was $5.3 \pm 4.79$ days; range $1-28$ days. The length of hospital stay did not correlate with increased risk of acquiring serious complications, $(t(86)=0.428, \mathrm{p}=0.670)$.

Despite the fact that most patients among the high risk group had an ANC of $<100$, this did not clinically translate into a high risk of serious complications and was also statistically insignificant ( $\chi^{2}$ test statistic: $1.87, \mathrm{df}=1, \mathrm{p}=0.17$ ).

The mean haemoglobin level was $9.7 \pm 2.1 \mathrm{~g} / \mathrm{dl}$ with lowest and highest level varying between 6.1 to $18.1 \mathrm{~g} / \mathrm{dl}$.

The factors associated with serious complications have been given in a cumulative form in Table 4.

\subsection{MASCC Score in Accurately Predicting Risk of Seriou Complications}

The sensitivity, specificity, positive and negative predictive value of MASCC score in accurately predicting risk of serious complications was $21.33 \%, 95 \% \mathrm{CI}$ [12.72 - 32.32], 100\%, 95\% CI [75.12 - 100], 100\%, 95\% CI [79.24 - 100] and 18.06\%, 95\% CI [9.99 - 28.90] respectively. See Table 5.

\section{Discussion}

This study helped us find that MASCC risk-index score as a useful tool to identify patients at low risk of complications. Eighty five percent patients comprised the high risk group which is higher than the proportion of patients reported in literature [27.5\% - 62\%] [15] [16]. Among the high risk patients 16 (21.33\%) developed serious complications while none of the patients in the low risk developed serious complications. This is in distinction to the results of similar studies in the past where $85 \%-86.3 \%$ patients in the high risk group developed serious medical complications. This indicates that the FN population in our part of the world is different from those reported in literature with less risk of developing serious complications. There is a potential that most of the low risk patients were not admitted. There are two possible explanations; one that their treating oncologists may have not admitted them because of their low risk predisposing 
Table 4. Factors associated with serious complications.

\begin{tabular}{|c|c|c|c|c|}
\hline \multirow{2}{*}{ Variable } & \multicolumn{2}{|c|}{ Serious Complications } & \multirow{2}{*}{ Test Statistic } & \multirow{2}{*}{$\mathrm{p}$ valu } \\
\hline & Yes & No & & \\
\hline Age & & & 4.256 & $0.039 \sim$ \\
\hline$<60$ & 9 & 58 & & \\
\hline$>60$ & 7 & 14 & & \\
\hline Gender & & & 0.256 & $0.613 \sim$ \\
\hline Male & 8 & 41 & & \\
\hline Female & 8 & 31 & & \\
\hline Tumor & & & 0.256 & $0.613 \sim$ \\
\hline Solid & 8 & 31 & & \\
\hline Heme & 8 & 41 & & \\
\hline Albumin* & & & 6.137 & $0.046 \sim$ \\
\hline$<2.5$ & 3 & 5 & & \\
\hline$>2.5$ & 8 & 21 & & \\
\hline ANC & & & - & $0.285 \S$ \\
\hline$<100$ & 15 & 57 & & \\
\hline$>100$ & 1 & 15 & & \\
\hline MASCC & & & - & $0.002 \S$ \\
\hline$\leq 15$ & 6 & 4 & & \\
\hline$>15$ & 10 & 68 & & \\
\hline Microbiology & & & 7.243 & $0.404 \sim$ \\
\hline Positive & 4 & 18 & & \\
\hline Negative & 11 & 55 & & \\
\hline G-CSF use & & & 2.144 & $0.143 \sim$ \\
\hline Yes & 12 & 64 & & \\
\hline No & 4 & 8 & & \\
\hline
\end{tabular}

${ }^{\star} \mathrm{A}$ baseline albumin was checked in 37 patients and not assessed in 51 patients. $\S$ Fischer Exact test. $\sim \chi^{2}$ test.

Table 5. MASCC score to predict presence or absence of serious medical complications.

\begin{tabular}{|c|c|c|c|}
\hline & MASCC Score & & \\
\hline Serious medical complications & High risk (+ve) & Low risk (-ve) & \\
\hline \multirow{2}{*}{ Present (+ve) } & True positive (a) & False Positive (b) & \\
\hline & 16 & 0 & 16 \\
\hline \multirow{2}{*}{ Absent (-ve) } & False Negative () & True Negative (d) & \\
\hline & 59 & 13 & 72 \\
\hline Total & 75 & 13 & $\mathrm{~N}=\mathbf{8 8}$ \\
\hline
\end{tabular}


features, second in view of Pakistan being a resource poor country these patients may not have reported to the hospital. Data regarding the patients with FN who presented in the outpatient setting and were not later admitted, would have helped in having a robust analysis, however such patients were not a part of this study as per our protocol.

In the original study by Klastersky et al., a score of $<15$ was associated with 79\% chance of serious complications, with MASCC score between 15 - 20 being intermediate in risk with $40 \%$ chance of complications [11]. In the current study similar results were found with $60 \%$ chance of serious complications in patients with a score of $<15 \%$ and $15.38 \%$ in patients with MASCC score amongst 15 20. A subsequent study may be done in the future to assess and stratify factors specific to this very high risk group (with MASCC score of $<15$, that predispose to higher rate of complications).

Among the 88 patients in this study, 22 had bacteraemia among which 13 (59\%) patients had gram negative bacteraemia and 9 (40\%) patients had gram positive bacteraemia. In the Western literature, the proportion of gram positive bacteraemia has increased in contrast to gram negative bacteraemia in patients with FN [17]. In a study by Feld et al., the factors predisposing to increased gram positive bacteraemia were said to be increased use of prophylactic antibiotics such as quinolones, central lines, antacids and mucositis (secondary to chemotherapy) [18]. In the developing countries, the situation of bacteraemia is similar to ours. [19] [20]. The reason for lower percentage of gram positive bacteraemia is thought to be due to less frequent use of quinolones and central lines [18]. In our study however prior history of prophylactic antibiotics and presence of central lines were not recorded.

Uys et al., in their study reported $75 \%$ mortality among the high risk bacteraemia patients. In the current study, however $11.7 \%$ in the high risk group with bacteraemia died.

There have been numerous randomized controlled trials to evaluate the efficacy of granulocyte colony stimulating factors (G-CSF) in FN patients, with results revealing effect on shortening the duration of neutropenia [21] [22] [23]. However none of the studies reveal benefit in terms of reducing the duration of fever, cost or the use of antimicrobial therapy and no effect on reducing mortality. In patients with uncomplicated FN episode, G-CSF is hence not recommended [24]. In our study the use of G-CSF was not associated with decrease in serious complications, $[\mathrm{p}=0.14]$.

There were several factors which were associated with a higher chance of developing serious complications. These factors included age $>60$, MASCC score of $<15$ and an albumin $<2.5 \mathrm{mg} / \mathrm{dl}$. However no statistically significant association was found in risk of developing serious complications based on solid or haematological malignancy, ANC, haemoglobin, gender, length of hospital stay and bacteraemia. In a similar study by Baskaran et al., low albumin was associated with a higher chance of serious complications [9]. However in contrast to the present study there was no statistically significant difference found based on 
age. Based on our results we recommend that albumin be incorporated in the risk stratification.

In our patient population the sensitivity, specificity, positive and negative predictive value of MASCC score in accurately predicting risk of serious complications was $21.33 \%, 100 \%, 100 \%$ and $18.06 \%$ respectively. In another study from Asia, sensitivity, specificity, negative and positive and negative predictive value of MASCC score in predicting risk of serious complications was 81, 60, 52 and $86 \%$ respectively [25]. In another study reported from Malaysia, MASCC score predicted outcome with sensitivity, specificity, and positive predictive value of $93 \%, 67 \%$ and $83 \%$ respectively [9]. By far in our patient population MASCC score was more specific and with a greater positive predictive value in comparison to other studies however less sensitive. This study correctly predicted $100 \%$ of low risk and $21.3 \%$ of high risk patients hence indicating that our high risk patient population need further risk stratification. A total of seventy five patients were predicted to be in the high risk MASCC group and sixteen of them developed serious medical complications. This lead to an obvious finding of a low sensitivity which is in contrast to those reported in earlier studies. This may be attributable to a relatively smaller sample size of our study or it could be a finding by chance alone. The low sensitivity of our study implies a possibility that our high risk group possibly developed less serious complications when compared to international data, or this again could be a chance finding. A probable explanation of this could be that our patient population is different. Another justification is that this study is only representative of a single institution and the inference thus is always taken with caution.

To the best of our knowledge through literature search, we report that this is the first study which applies the MASCC score index in our patient population, from the developing country belt.

There are several strengths of this study; a cohort study design was selected which is ideal in forecasting the causal association of exposure with outcome. Furthermore there was no loss in follow up or drop out of our cohort as these patients were followed up till hospital discharge. Our study has few limitations that need to be taken into account while interpreting the results. As we enrolled all the patients with febrile neutropenia during the study period hence it was hard to select and maintain an equal number of exposed and non-exposed patients. It shall be recognized that this is a single centre study conducted in a tertiary care centre. Hence, generalizability of our study results is reported with caution.

\section{Unanswered Questions and Future Directions for Research}

Data regarding the patients with FN who presented in the outpatient setting and were not later admitted, would have helped in a robust data analysis, however such patients were not a part of this study.

Among the patients identified to be in the low risk group a prospective study could be done to treat them with oral antibiotics with possibility of an early dis- 
charge if a patient remains afebrile for more than 24 hours. This would help in reducing length of hospital stay and hence cost of medical treatment. Similar study has been done in the past by Klastersly et al., in which $44 \%$ low risk patients eligible for oral antibiotics were discharged home with a median time to discharge of 26 hours after they were afebrile for at least 24 hours [26]. Only $3.7 \%$ of these patients required readmission, however none of the $44 \%$ patients developed any serious medical complications [26].

\section{Conclusion}

We conclude that MASCC risk index score is a tool which is helpful in identifying FN patients at low risk of complications. In future by applying this score it would help in treating high risk patients aggressively from the start and at the same time identifying low risk patients who may be treated less aggressively with a potential early discharge and marked reduction in hospital cost.

\section{Acknowledgements}

The authors would like to thank all participating subjects. We would also like to acknowledge Miss. Naseem Samson who helped us in formatting of the tables and figure in the article.

\section{Competing Interests}

The authors declare that they have no competing interests.

\section{Funding}

This research study was not funded by any funding source.

\section{Authors' Contributions}

Z.S. primarily initiated the concept of the study. Z.S., M.B. and M.S. have made substantial contributions to conception and development of project, design, analysis and interpretation of data. Z.S. and M.B. performed the data analysis.

M.K. was responsible for acquisition of data. Z.S. drafted the initial manuscript; A.A. and A.D. helped in reviewing the article. M.B. and M.S. were involved in critically revising and adding intellectual content to the final version. All authors carefully reviewed and approved the final document.

\section{References}

[1] Hughes, W.T., Armstrong, D., Bodey, G.P., Bow, E.J., Brown, A.E., Calandra, T., et al. (2002) 2000 Guidelines for the Use of Antimicrobial Agents in Neutropenic Patients with Cancer. Clinical Infectious Diseases, 34, 730-751. https://doi.org/10.1086/339215

[2] Klastersky, J. (2004) Management of Fever in Neutropenic Patients with Different Risks of Complications. Clinical Infectious Diseases, 39, S32-S37. https://doi.org/10.1086/383050

[3] Bodey, G.P., Buckley, M., Sathe, Y.S. and Freireich, E.J. (1966) Quantitative Rela- 
tionships between Circulating Leukocytes and Infection in Patients with Acute Leukemia. Annals of Internal Medicine, 64, 328-340.

http://annals.org/aim/article/680517/quantitative-relationships-between-circulating -leukocytes-infection-patients-acute-leukemia https://doi.org/10.7326/0003-4819-64-2-328

[4] Ramphal, R. (2004) Changes in the Etiology of Bacteremia in Febrile Neutropenic Patients and the Susceptibilities of the Currently Isolated Pathogens. Clinical Infectious Diseases, 39, S25-S31. https://doi.org/10.1086/383048

[5] Rosenberg, P.S., Alter, B.P., Bolyard, A.A., Bonilla, M.A., Boxer, L.A., Cham, B., et al. (2006) The Incidence of Leukemia and Mortality from Sepsis in Patients with Severe Congenital Neutropenia Receiving Long-Term G-CSF Therapy. Blood, 107, 4628-4635. https://doi.org/10.1182/blood-2005-11-4370

[6] Lyman, G.H., Morrison, V.A., Dale, D.C., Crawford, J., Delgado, D.J., Fridman, M., et al. (2003) Risk of Febrile Neutropenia among Patients with Intermediate-Grade Non-Hodgkin's Lymphoma Receiving CHOP Chemotherapy. Leukemia \& Lymphoma, 44, 2069-2076. https://doi.org/10.1080/1042819031000119262

[7] Kuderer, N.M., Dale, D.C., Crawford, J., Cosler, L.E. and Lyman, G.H. (2006) Mortality, Morbidity, and Cost Associated with Febrile Neutropenia in Adult Cancer Patients. Cancer, 106, 2258-2266.

http://onlinelibrary.wiley.com/doi/10.1002/cncr.21847/full

https://doi.org/10.1002/cncr.21847

[8] de Naurois, J., Novitzky-Basso, I., Gill, M.J., Marti, F.M., Cullen, M.H., Roila, F., et al. (2010) Management of Febrile Neutropenia: ESMO Clinical Practice Guidelines. Annals of Oncology, 21, v252-v256. https://doi.org/10.1093/annonc/mdq196

[9] Baskaran, N.D., Gan, G.G. and Adeeba, K. (2008) Applying the Multinational Association for Supportive Care in Cancer Risk Scoring in Predicting Outcome of Febrile Neutropenia Patients in a Cohort of Patients. Annals of Hematology, 87, 563 569. https://doi.org/10.1007/s00277-008-0487-7

[10] Talcott, J.A., Siegel, R.D., Finberg, R. and Goldman, L. (1992) Risk Assessment in Cancer Patients with Fever and Neutropenia: A Prospective, Two-Center Validation of a Prediction Rule. Journal of Clinical Oncology, 10, 316-322.

http://ascopubs.org/doi/pdf/10.1200/JCO.1992.10.2.316

https://doi.org/10.1200/JCO.1992.10.2.316

[11] Klastersky, J., Paesmans, M., Rubenstein, E.B., Boyer, M., Elting, L., Feld, R., et al. (2000) The Multinational Association for Supportive Care in Cancer Risk Index: A Multinational Scoring System for Identifying Low-Risk Febrile Neutropenic Cancer Patients. Journal of Clinical Oncology, 18, 3038-3051.

http://ascopubs.org/doi/pdf/10.1200/JCO.2000.18.16.3038

https://doi.org/10.1200/JCO.2000.18.16.3038

[12] Kern, W.V., Marchetti, O., Drgona, L., Akan, H., Aoun, M., Akova, M, et al. (2013) Oral Antibiotics for Fever in Low-Risk Neutropenic Patients with Cancer: A Double-Blind, Randomized, Multicenter Trial Comparing Single Daily Moxifloxacin with Twice Daily Ciprofloxacin plus Amoxicillin/Clavulanic Acid Combination Therapy-EORTC Infectious Diseases Group Trial XV. Journal of Clinical Oncology, 31, 1149-1156. https://doi.org/10.1200/JCO.2012.45.8109

[13] Inouye, S.K., van Dyck, C.H., Alessi, C.A., Balkin, S., Siegal, A.P. and Horwitz, R.I. (1990) Clarifying Confusion: The Confusion Assessment Method. A New Method for Detection of Delirium. Annals of Internal Medicine, 113, 941-948.

http://citeseerx.ist.psu.edu/viewdoc/download?doi=10.1.1.477.4525\&rep=rep1\&type $=\mathrm{pdf}$

https://doi.org/10.7326/0003-4819-113-12-941 
[14] Khwaja, A. (2012) KDIGO Clinical Practice Guidelines for Acute Kidney Injury. Nephron Clinical Practice, 120, c179-c184. https://doi.org/10.1159/000339789

[15] Uys, A., Rapoport, B.L. and Anderson, R. (2004) Febrile Neutropenia: A Prospective Study to Validate the Multinational Association of Supportive Care of Cancer (MASCC) Risk-Index Score. Supportive Care in Cancer, 12, 555-560.

https://www.ncbi.nlm.nih.gov/labs/articles/15197637/ https://doi.org/10.1007/s00520-004-0614-5

[16] Cherif, H., Johansson, E., Bjorkholm, M. and Kalin, M. (2006) The Feasibility of Early Hospital Discharge with Oral Antimicrobial Therapy in Low Risk Patients with Febrile Neutropenia Following Chemotherapy for Hematologic Malignancies. Haematologica, 91, 215-222. http://www.haematologica.org/content/91/2/215

[17] Klastersky, J. (1998) Science and Pragmatism in the Treatment and Prevention of Neutropenic Infection. The Journal of Antimicrobial Chemotherapy, 41, 13-24.

https://doi.org/10.1093/jac/41.suppl_4.13

[18] Feld, R. (2008) Bloodstream Infections in Cancer Patients with Febrile Neutropenia. The International Journal of Antimicrobial Agents, 32, S30-S33. https://doi.org/10.1016/j.ijantimicag.2008.06.017

[19] Kanafani, Z.A., Dakdouki, G.K., El-Chammas, K.I., Eid, S., Araj, G.F. and Kanj, S.S. (2007) Bloodstream Infections in Febrile Neutropenic Patients at a Tertiary Care Center in Lebanon: A View of the Past Decade. The International Journal of Infectious Diseases, 11, 450-453. https://doi.org/10.1016/j.ijid.2006.12.008

[20] Baskaran, N.D., Gan, G.G., Adeeba, K. and Sam, I.C. (2007) Bacteremia in Patients with Febrile Neutropenia after Chemotherapy at a University Medical Center in Malaysia. The International Journal of Infectious Diseases, 11, 513-517. https://doi.org/10.1016/j.ijid.2007.02.002

[21] Biesma, B., de Vries, E.G., Willemse, P.H., Sluiter, W.J., Postmus, P.E., Limburg, P.C., et al. (1990) Efficacy and Tolerability of Recombinant Human GranulocyteMacrophage Colony-Stimulating Factor in Patients with Chemotherapy-Related Leukopenia and Fever. European Journal of Cancer, 126, 932-936. https://www.ncbi.nlm.nih.gov/pubmed/2149017

[22] Ravaud, A., Chevreau, C., Cany, L., Houyau, P., Dohollou, N., Roche, H., et al. (1998) Granulocyte-Macrophage Colony-Stimulating Factor in Patients with Neutropenic Fever Is Potent after Low-Risk but Not after High-Risk Neutropenic Chemotherapy Regimens: Results of a Randomized Phase III Trial. Journal of Clinical Oncology, 16, 2930-2936. https://doi.org/10.1200/JCO.1998.16.9.2930

[23] Maher, D.W., Lieschke, G.J., Green, M., Bishop, J., Stuart-Harris, R., Wolf, M., et al. (1994) Filgrastim in Patients with Chemotherapy-Induced Febrile Neutropenia. A Double-Blind, Placebo-Controlled Trial. Annals of Internal Medicine, 121, 492-501. https://doi.org/10.7326/0003-4819-121-7-199410010-00004

[24] Ozer, H., Armitage, J.O., Bennett, C.L., Crawford, J., Demetri, G.D., Pizzo, P.A., et al. (2000) 2000 Update of Recommendations for the Use of Hematopoietic ColonyStimulating Factors: Evidence-Based, Clinical Practice Guidelines. American Society of Clinical Oncology Growth Factors Expert Panel. Journal of Clinical Oncology, 18, 3558-3585. http://ascopubs.org/doi/pdf/10.1200/JCO.2000.18.20.3558 https://doi.org/10.1200/JCO.2000.18.20.3558

[25] Hui, E.P., Leung, L.K., Poon, T.C., Mo, F., Chan, V.T., Ma, A.T., et al. (2011) Prediction of Outcome in Cancer Patients with Febrile Neutropenia: A Prospective Validation of the Multinational Association for Supportive Care in Cancer Risk Index in a Chinese Population and Comparison with the Talcott Model and Artificial Neural Network. Supportive Care in Cancer, 19, 1625-1635. 
https://doi.org/10.1007/s00520-010-0993-8

[26] Klastersky, J., Paesmans, M., Georgala, A., Muanza, F., Plehiers, B., Dubreucq, L., et al.(2006) Outpatient Oral Antibiotics for Febrile Neutropenic Cancer Patients Using a Score Predictive for Complications. Journal of Clinical Oncology, 24, 4129-4134. https://doi.org/10.1200/JCO.2005.03.9909 


\section{List of Abbreviations}

ANC

ALL

AML

AKUH

CI

DLBCL

ERC

FN

G-CSF

MASCC

PCP

PTT

SPSS

TMP-SMZ
Absolute Neutrophil Count

Acute Lymphoblastic Leukemia

Acute Myeloid Leukemia

Aga Khan University Hospital

Confidence Intervals

Diffuse Large B-Cell Lymphoma

Ethical Review Committee

Febrile Neutropenia

Granulocyte Colony Stimulating Factors

Multinational Association of Supportive Care of Cancer

Pneumocystis carinii pneumonia

Prothrombin Thromboplaistn Time

Statistical Packages for Social Sciences

Trimethoprim-Sulfamethoxazole

Submit or recommend next manuscript to SCIRP and we will provide best service for you:

Accepting pre-submission inquiries through Email, Facebook, LinkedIn, Twitter, etc. A wide selection of journals (inclusive of 9 subjects, more than 200 journals)

Providing 24-hour high-quality service

User-friendly online submission system

Fair and swift peer-review system

Efficient typesetting and proofreading procedure

Display of the result of downloads and visits, as well as the number of cited articles

Maximum dissemination of your research work

Submit your manuscript at: http://papersubmission.scirp.org/

Or contact ojepi@scirp.org 